\title{
Nonlinear Connection Stiffness Identification of Heritage Timber Buildings Using a Temperature-Driven Multi-model Approach
}

\author{
Qingshan Yang ${ }^{1}$, Mengning Lyu ${ }^{2}$ and Xinqun Zhu ${ }^{* 3}$ \\ ${ }^{I}$ School of Civil Engineering, Chongqing University, Chongqing, China. \\ ${ }^{2}$ Beijing's Key Laboratory of Structural Wind Engineering and Urban Wind Environment, \\ School of Civil Engineering, Beijing Jiaotong University, Beijing, China. \\ ${ }^{3}$ School of Civil and Environmental Engineering, University of Technology Sydney, Sydney, NSW 2007, \\ Australia.Corresponding author:xinqun.zhu@uts.edu.au
}

\begin{abstract}
'Que-Ti' is an important component in typical Tibetan heritage timber buildings and it performs similar to corbel brackets connecting beam and column in modern structures. It transfers shear, compression and bending moment by slippage and deformation of components as well as limited joint rotation. A rigorous analytical model of 'Que-Ti' is needed for predicting the behaviour of a timber structure under extreme loadings. Few research has been done on this topic, particularly with the parameters describing the performances of this connection subjected to external loads. In this paper, a new temperature-driven multimodel approach is proposed to identify the stiffness parameters of a 'Que-Ti' connection in its operating environment. Models with nonlinear compression and rotational springs have been developed to take into account the change of mechanical behaviour of the 'Que-Ti' affected by the temperature variation in typical heritage Tibetan buildings. The column-beam connection is modeled as two nonlinear rotational springs and one nonlinear compressive spring. Ambient temperature variation is treated as a force function in the input (temperature) - output (local mechanical strains) relationship, and stiffness identification is conducted iteratively via correlating the calculated strain responses with measured data. The nonlinear model of the joint is reproduced with a number of linear local models in different deformation scenarios that are corresponding to different temperature ranges. The stiffness paarmeters can be identified using a multimodel approach. Numerical results show that the method is effective and reliable to identify the nonlinear connection stiffness of the 'Que-Ti' accurately with the temperature change even with $10 \%$ noise in measurements. The monitoring data from a long-term monitoring system installed in a typical heritage Tibetan building is used to further verify the method. The experimental results show that the identified stiffness by the proposed method with nonlinear connection stiffness model can get better results than that obtained from the linear connection stiffness model.
\end{abstract}


Keywords: heritage building, nonlinear connection stiffness identification, temperature variation, response sensitivity

\section{Introduction}

The architectural heritages have very important historical, cultural, and artistic values. Due to the changing environment and aging, condition assessment of these heritage buildings is becoming increasingly important for their safety (De Stefano et al., 2016; Riggio and Dilmaghani, 2019). 'Que-Ti' connection, as shown in Figure 1, is acting used as a beam-tocolumn joint in typical Tibetan heritage timber buildings which are over thousands of years old. It is a key component for transfering shear, compression, and bending loads from one structural element to another in this type of building. However, little can be found in the literature on structural stiffness parameters of this connection. For the safety of these buildings, it urgently needs to develop an effective approach to assess the condition of this joint in the operational environment.

Many researches have been conducted on structural identification from dynamic measurements using model-based methods (Aktan et al. 1997; Brownjohn et al. 2003; Link and Weiland, 2009). Most of these studies utilised structural dynamic responses to identify structural parameters in time domain. The vibration response time history was adopted for structural identification (Cattarius and Inman, 1997). Structural stiffness parameters of a multi-storey framework were identified in a system identification approach (Koh et al. 2000). Recently, the dynamic response sensitivity-based model updating method has been developed and used to identify structural parameters from the dynamic response measurements (Lu and Law 2007; Lu and Wang 2017). Only a few measuring points are needed, and they provide highly accurate parameter identification taking advantage of the abundant time history data. The success of the model-based approach is mainly governed by the quality of the numerical model and it is very sensitive to uncertainties, such as modelling errors, measurement noise and variations of operational environments. The modelling errors are largely independent of any inherent shortcomings of the simulation tools adopted, but rather, due to a lack of knowledge of the target structure (Yarnold et al. 2015). For herititage timber buildings, there are lots of uncertainties due to the irregularity of the internal timber texture, the variety of joint stiffness, exisiting cracks and the effects of undocumented damage and repairs. Another challenge for structural identification is the effect of operational environments, especially temperature. 
Structural parameter identification based on a reference set of measured data is usually subjected to the environmental temperatures in the two sets of measurements. Such effect is usually ignored in the subsequent model updating (Wei and Lv, 2015). Past researches have illustrated the structural health monitoring with the consideration of the temperature effects in structural monitoring (Catbas et al. 2008; Burdet et al. 2010; Cao et al. 2011). The variation of intrinsic forces due to thermal and other mechanisms can mask the effects from all other demands. Previous studies indicated the presence of large changes in these intrinsic forces over time but the detail mechanisms that give rise to these forces are not available (Catbas and Aktan 2002). Based on the long-term monitoring data, less than $3 \%$ of total strain are caused by dynamic loads such as crowded and wind loadings (Dai et al., 2016). The strain response is mainly induced by the temperature variation. As discussed above, the structural identification from dynamic measurements is not properly for predicting the connection stiffness of the beamcolumn connection in heritage timber buildings.

Recently, there is an increasing interest to directly utilise the temperature-related responses for structural identification. The thermal-induced response is a pseudo-static proess and the damping and dynamic effects need not to be considered. Kulprapha and Warnitchai (2012) investigated the feasibility to monitor the structural health of multi-span pre-stressed concrete bridges using the ambient thermal loads and responses, such as strains, deflections and support reaction forces etc. Yarnold and Moon (2015) created the structural health monitoring baseline by utilizing the relationship between temperature changes and the strain/displacement responses. The stiffness parameter of 'Que-Ti' has been studied with considering the temperature effect by Lyu et al (2017a) and a temperature based sensitivity analysis method has been developed to identify the joint stiffness. Zhu et al. (2019) extracted the temperatureinduced strain response using moving principal component analysis for structural damage detection. The results showed that the temperature-driven approach is much sensitive in structural damage detection.

'Que-Ti' and the mortise and tenon connection of two beams at its top in Tibetan heritage timber buildings are the typical semi-rigid beam-column joints. This connection is essential to be the nonlinear behaviour of wooden structure under the applied load (Xie et al., 2018). The linear model is imprecise to reproduce the nonlinear behaviour of the joint and the nonlinear system identification method needs to be developed for identification of the joint stiffness parameters. The multimodel approach is widely used for identification of complex, nonlinear, uncertain systems (Adebowale and El Ferik, 2017). The global system model is formed by a 
set of local linear models in different operational regions. Cao et al. (2015) presented a simplified analytical model to analyse the nonlinear behaviour of a two-layer wooden beam system. There are four deformation sciencios to describe the load resistence based on the state of friction between the two layers and the state of shear at the connection. Each deformation sciencio can be described by a linear local model. In practice, the beam-column joint in Tibetan timber buildings is much complicated (Wang et al., 2017) and more deformation sciencios needs to be considered in the global model. Lyu et al. (2017b) used a simplified bilinear model to consider the connection between two layers by two deformation scenarios and the joint stiffness is identified using the temperature-based sensitivity analysis. This approach will be extended to identified nonlinear stiffness parameters of the joint.

In this paper, a temperature-driven multimodel method is developed to identify the connection stiffness of the semi-rigid joint in typical historic Tibetan buildings from measured strain responses and temperatures. The 'Que-Ti' connection is modelled by two nonlinear rotational springs and one nonlinear compressive spring. The global nonlinear model is separated into a number of linear local models for different operating regions. The stiffness of connection is identified separately with varying temperature taking into account the temperature effects on the mechanical behaviour of 'Que-Ti'. The temperature of structure is monitored and the thermal loading on the structure is obtained from the temperature change. This thermal loading is the excitation input to the structural system and the measured strain response is the output. Structural parameters are determined using the temperature-based response sensitivity. A twodimensional frame model is adopted to study the accuracy and reliability of the proposed method. The numerical results show that the stiffness of the 'Que-Ti' can be identified accurately with temperature change in the time domain even with $10 \%$ noise in the strain measurements. A long-term monitoring system installed in a typical Tibetan heritage building provided field measured data for verification of the proposed method. The dynamic effect in the measured data is removed by the moving average and low-pass filter. The identified results from using the proposed nonlinear connection model are more accurate than those from a linear connection model (Lyu et al. 2017a).

\section{Nonliear model of the 'Que-Ti'}

One of the unique characteristics of typical Tibetan heritage timber structures is the existence of 'Que-Ti' as connections transferring load between beam and column via an increase in the bearing area at the end of the beam, and a decrease of the beam span leading to an improved 
shear and bending resistance at the beam end. It seldom involves nails or pins in its construction (Fang et al., 2001). The beam-column joint of a heritage timber architecture, as shown in Figure 1 , is typically a planar structural component supporting column from the top and beams coming in from two horizontal directions which are discontinuous at the top of the column as shown in Figure 2(a). The connection of two beams is a typical mortise and tenon connection. The parts between the top beam and the column form the 'Que-Ti' that includes three layers connected by short wooden sticks. The deformation of the beam is limited by the wooden stick fit into a hole, which is shown with the dark rectangular square in Figure 2(b). The wooden stick and the hole in the connection are called tenon and mortise respectively. Due to fabrication error and shrinkage distortion of wood, there will be a gap between the mortise and tenon, denote as $s$ as shown in Figure 2(b). The frictional slip and the relative longitudinal displacement at the contact surface between the beam and connection will occur under external loads. When the

relative longitudinal displacement is larger than the gap, the tenon will be subjected to the longitudinal shear which contributes to the load resistance of the layered beam. The location, range of slip and the distribution of the friction force vary with the external loading. Therefore, it is a typical example of the nonlinear beam-column connection.

With consideration of this connection arrangement and the inelastic behaviour of timber material under temperature variation, three nonlinear and uncoupled springs are used to simulate the behaviour of a 'Que-Ti'. Two of them are rotational springs with stiffnesses $\mathrm{K}_{2}$ and $\mathrm{K}_{3}$ to simulate the behaviour of the rotating restraint (the horizontal displacement is not considered in this study) on the beam, and the other one with stiffness $\mathrm{K}_{1}$ modeling the vertical compressive stiffness to simulate the compression behaviour perpendicular to grain as shown in Figure 3 (Code for design of timber structures).

\section{Nonlinear system identification with a temperature-driven multi-model approach}

\subsection{A multimodel approach for modelling the nonlinear behaviour of 'Que-Ti'}

As discussed in Section 2, the 'Que-Ti' is a typical nonlinear beam-column connection. Cao et al. (2015) proposed a nonlinear analytical model of the two-layer wooden beam system with four deformation scenarios of the load resisting mechanism. Each deformation scenario is described as one local linear model. As shown in Figure 2(a), 'Que-Ti' is a connection with three layers and it also connects with the top beam by short wooden sticks. The beam-column connection is much complicated and it cannot be described using a nonlinear analytical model. In this study, the entire behaviour of the nonlinear system is separated into a number of 
operating regions that are corresponding to different temperature rages. A local linear model is used to reproduce the behaviour of the system in each operating region, which is called the deformation scenario.

Figure 4 shows the strain measurements with changes in the ambient temperature in a typical Tibetan heritage building. The measurement data have been smoothed through the moving average and low-pass filter to remove the dynamic effect.. The information of instrumentation and location of sensors will be discussed in following section. Figures 4(a) and 4(c) show strain responses and temperature measurements of the beam over one day and one year, respectively. The measurements on the column over one day and one year are shown in Figures 4(b) and 4(d). The plots show clearly that structural strain responses closely follow the temperature cycle implying that temperature variations play a key role to the deformations in these components. The temperature versus strain response appears to approximate a correlate relationship, which can be seen in Figure 4(e). The structural response of a building may be approximated as a function of temperature and the temperature response is sufficient to enable interpretation of measurements from long-term monitoring. The relationship between the strain measurement and the ambient temperature change is noted nonlinear. By the multimodel approach, it can be modelled as piecewise linear model over a short temperature interval in a temperature-dependent form. This relationship is writtenn a linear equation for a given scenario of temperature interval.

As above, the entire behaviour of the nonlinear system is separated into $M_{S}$ scenarios and each scenario is defined by a linear local model. The global response of the system is the combination of the local model responses. The multimodel formulation of the system can be written as

$$
\left[\boldsymbol{\varepsilon}_{i}\right]=\sum_{S_{1}=1}^{M_{S}}\left[\varepsilon_{i}\right]_{S_{1}} \quad(i=1,2, \cdots, n)
$$

where $\left[\varepsilon_{i}\right]$ and $\left[\varepsilon_{i}\right]_{S_{1}}$ are the global strain response of the system and the linear local model response of Scenario $\mathrm{S}_{1}$ at the $\mathrm{i}^{\text {th }}$ time step. $n$ is the total time steps.

\subsection{Structural parameter identification using a temperature-driven multimodel approach}

For Scenario $\mathrm{S}_{1}$, it can be defined as a general finite element model of a linear elastic timevariant system with $m$ elements, and the equation of the strain caused by the thermal loading variation is given as 


$$
\left[\boldsymbol{\varepsilon}_{i}\right]_{S_{1}}=[\boldsymbol{B}][\boldsymbol{K}]_{S_{1}}^{-1}\left[\boldsymbol{F}_{i}\right]_{S_{1}} \quad(i=1,2, \cdots, n)
$$

where $[\mathbf{B}]$ and $[\boldsymbol{K}]_{S_{1}}$ are the system strain-displacement relation matrix and the stiffness matrix of Senario $S_{1}$ respectively. $\left[\boldsymbol{\varepsilon}_{i}\right]_{S_{1}}$ and $\left[\boldsymbol{F}_{i}\right]_{S_{1}}$ are the strain and the external thermal load of the system at the $\mathrm{i}^{\text {th }}$ time step in Scenario $\mathrm{S}_{1}$ respectively.

The uniform temperature effect on different finite element has been considered in this study. Different thermal load in different element can be achieved based on sufficient measurement points and finite element mesh density. Since the temperature variation is treated as a force function in this study, Eq. (2) can be further rewritten as

$$
\left[\begin{array}{c}
\varepsilon_{i}^{1} \\
\varepsilon_{i}^{2} \\
\vdots \\
\varepsilon_{i}^{m-1} \\
\varepsilon_{i}^{m}
\end{array}\right]=[\boldsymbol{B}][\boldsymbol{K}]_{S_{1}}^{-1}\left[\begin{array}{c}
\alpha_{1} E_{1} A_{1} \Delta T_{i}^{1} \\
\alpha_{2} E_{2} A_{2} \Delta T_{i}^{2} \\
\vdots \\
\alpha_{m-1} E_{m-1} A_{m-1} \Delta T_{i}^{m-1} \\
\alpha_{m} E_{m} A_{m} \Delta T_{i}^{m}
\end{array}\right]_{S_{1}} \quad(i=1,2, \cdots, n)
$$

where $\Delta T_{i}^{j}$ is the temperature variation of the $\mathrm{j}^{\text {th }}$ element at the $\mathrm{i}^{\text {th }}$ time step. $\alpha_{j}, \mathrm{E}_{j}, \mathrm{~A}_{j}$ are the material thermal expansion coefficient, the modulus of elasticity and the cross sectional area of the $j$ th element respectively.

The difference between the measured and calcuated responses can be obtained as

$$
[\Delta \boldsymbol{R}]_{S_{1}}=[\boldsymbol{\varepsilon}]_{\text {Cal_S }_{1}}-[\boldsymbol{\varepsilon}]_{\text {Meas } S_{1}}=[\boldsymbol{B}][\boldsymbol{K}]_{S_{1}}^{-1}\left[\begin{array}{c}
\alpha_{1} E_{1} A_{1} \Delta T_{i}^{1} \\
\alpha_{2} E_{2} A_{2} \Delta T_{i}^{2} \\
\vdots \\
\alpha_{m-1} E_{m-1} A_{m-1} \Delta T_{i}^{m-1} \\
\alpha_{m} E_{m} A_{m} \Delta T_{i}^{m}
\end{array}\right]_{S_{1}}-\left[\begin{array}{c}
\varepsilon_{i}^{1} \\
\varepsilon_{i}^{2} \\
\vdots \\
\varepsilon_{i}^{m-1} \\
\varepsilon_{i}^{m}
\end{array}\right]_{\text {Meas } S_{1}}
$$

where $[\boldsymbol{\varepsilon}]_{\text {Cal }_{-} S_{1}},[\boldsymbol{\varepsilon}]_{\text {Meas } S_{1}}$ are calculated and measured response of Scenario $\mathrm{S}_{1}$.

Differentiating both sides of Equation (3) with respect to the stiffness parameter the system will give

$$
\frac{\partial[\varepsilon]_{S_{1}}}{\partial p_{j}}=[\boldsymbol{B}][\boldsymbol{K}]_{S_{1}}^{-1} \frac{\partial[\boldsymbol{K}]_{S_{1}}}{\partial p_{j}}[\boldsymbol{K}]_{S_{1}}^{-1}\left[\begin{array}{c}
\alpha_{1} E_{1} A_{1} \Delta T_{i}^{1} \\
\alpha_{2} E_{2} A_{2} \Delta T_{i}^{2} \\
\vdots \\
\alpha_{m-1} E_{m-1} A_{m-1} \Delta T_{i}^{m-1} \\
\alpha_{m} E_{m} A_{m} \Delta T_{i}^{m}
\end{array}\right]_{S_{1}} \quad(i=1,2 \ldots, n)
$$


where $\left\{p_{j}, i=1,2, \cdots, m\right\}$ are unknown stiffness parameters of m elements. $\partial / \partial$ is the first derivative.

The strain residual sensitivity matrix can be written as

$$
[\boldsymbol{S}]_{j_{-} S_{1}}=\left[\frac{\partial \varepsilon}{\partial p_{j}}\right]_{S_{1}}=[\boldsymbol{B}][\boldsymbol{K}]_{S_{1}}^{-1} \frac{\partial[\boldsymbol{K}]_{S_{1}}}{\partial p_{j}}[\boldsymbol{K}]_{S_{1}}^{-1}\left[\begin{array}{c}
\alpha_{1} E_{1} A_{1} \Delta T_{i}^{1} \\
\alpha_{2} E_{2} A_{2} \Delta T_{i}^{2} \\
\vdots \\
\alpha_{m-1} E_{m-1} A_{m-1} \Delta T_{i}^{m-1} \\
\alpha_{m} E_{m} A_{m} \Delta T_{i}^{m}
\end{array}\right]_{S_{1}}
$$

The length of the sensitivity vector is the same as the number of measured data points, and the sensitivity vector corresponding to a fractional change of stiffness in the $j^{\text {th }}$ element can be rewritten as $[\boldsymbol{S}]_{j_{-} S_{1}}$. The sensitivity vectors for all structural elements can be computed for Scenario $\mathrm{S}_{1}$, and the sensitivity matrix is assembled as

$$
\boldsymbol{S}_{S_{1}}=\left\{\left[\begin{array}{lllll}
{\left[\boldsymbol{S}_{1_{-} S_{1}}\right.} & {\left[\boldsymbol{S}_{2_{-} S_{1}}\right.} & \cdots & {[\boldsymbol{S}]_{(m-1) \_} S_{1}} & {[\boldsymbol{S}}
\end{array}\right]_{m \_} S_{1}\right\}
$$

Based on Eqs. (4), (6) and (7), the identification equation on the stiffness parameters of a structure can be written as

$$
\left[\begin{array}{ccccc}
\frac{\partial \boldsymbol{\varepsilon}_{1}}{\partial p_{1}} & \frac{\partial \boldsymbol{\varepsilon}_{1}}{\partial p_{2}} & \cdots & \frac{\partial \boldsymbol{\varepsilon}_{1}}{\partial p_{m-1}} & \frac{\partial \boldsymbol{\varepsilon}_{1}}{\partial p_{m}} \\
\frac{\partial \boldsymbol{\varepsilon}_{2}}{\partial p_{1}} & \frac{\partial \boldsymbol{\varepsilon}_{2}}{\partial p_{2}} & \cdots & \frac{\partial \boldsymbol{\varepsilon}_{2}}{\partial p_{m-1}} & \frac{\partial \boldsymbol{\varepsilon}_{2}}{\partial p_{m}} \\
\vdots & \vdots & \vdots & \vdots & \vdots \\
\frac{\partial \boldsymbol{\varepsilon}_{n-1}}{\partial p_{1}} & \frac{\partial \boldsymbol{\varepsilon}_{n-1}}{\partial p_{2}} & \cdots & \frac{\partial \boldsymbol{\varepsilon}_{n-1}}{\partial p_{m-1}} & \frac{\partial \boldsymbol{\varepsilon}_{n-1}}{\partial p_{m}} \\
\frac{\partial \boldsymbol{\varepsilon}_{n}}{\partial p_{1}} & \frac{\partial \boldsymbol{\varepsilon}_{n}}{\partial p_{2}} & \cdots & \frac{\partial \boldsymbol{\varepsilon}_{n}}{\partial p_{m-1}} & \frac{\partial \boldsymbol{\varepsilon}_{n}}{\partial p_{m}}
\end{array}\right]_{S_{1}} \quad\left\{\begin{array}{c}
\Delta p_{1 \_S_{1}} \\
\Delta p_{2_{-} S_{1}} \\
\vdots \\
\Delta p_{m-1 S_{1}} \\
\Delta p_{m \_} S_{1}
\end{array}\right\}=\left\{\begin{array}{c}
\Delta \boldsymbol{R}_{1 \_S_{1}} \\
\Delta \boldsymbol{R}_{2 \_} S_{1} \\
\vdots \\
\Delta \boldsymbol{R}_{m-1 S_{1}} \\
\Delta \boldsymbol{R}_{m \_} S_{1}
\end{array}\right\}
$$

or in short

$$
\boldsymbol{S}_{S_{1}} \Delta \boldsymbol{P}_{S_{1}}=\Delta \boldsymbol{R}_{S_{1}}
$$

where $\Delta \boldsymbol{P}_{S_{1}}=\left\{\begin{array}{llll}\Delta p_{1 \_} S_{1} & \Delta p_{2 \_} S_{1} & \cdots & \Delta p_{m_{-} S_{1}}\end{array}\right\}^{T}$ is the unknown incremental parameters in Scenario $\mathrm{S}_{1 .} \Delta \boldsymbol{R}_{S_{1}}=\left\{\begin{array}{llll}\Delta \boldsymbol{R}_{1 \_} S_{1} & \Delta \boldsymbol{R}_{2 \_} S_{1} & \cdots & \Delta \boldsymbol{R}_{m_{-} S_{1}}\end{array}\right\}^{T}$ is the difference between the measured and reconstructed response in Scenario $\mathrm{S}_{1} . \boldsymbol{S}_{S_{1}}=\left\{\frac{\partial \varepsilon_{i}}{\partial p_{j}}, i=1,2,3, \cdots, n ; j=1,2, \cdots, m\right\}$ is the sensitivity matrix. 
Eq. (8) can be solved with an iterative Gauss-Newton method described below, and Tikhonov regularization is used for optimizing the following objective function in the $k^{\text {th }}$ iteration as

$$
\begin{array}{r}
\boldsymbol{P}_{k_{-} S_{1}}=\boldsymbol{P}_{k-1_{-} S_{1}}+\left[\boldsymbol{S}_{k_{-} S_{1}}^{T} \boldsymbol{S}_{k_{-} S_{1}}\right]^{-1} \boldsymbol{S}_{k_{-} S_{1}}^{T} \Delta \boldsymbol{R}_{S_{1}} \\
J_{S_{1}}\left(\Delta \boldsymbol{P}_{k_{-} S_{1}}, \lambda_{k_{-} S_{1}}\right)=\left\|\boldsymbol{S}_{k-1 \_S_{1}} \Delta \boldsymbol{P}_{k_{-} S_{1}}-\Delta \boldsymbol{R}_{S_{1}}\right\|+\lambda_{k_{-} S_{1}}\left\|\Delta \boldsymbol{P}_{k_{-} S_{1}}\right\|^{2}
\end{array}
$$

where $\lambda_{k_{-} s_{1}}$ is the regularization parameter in the $k^{\text {th }}$ iteration obtained with the L-curve method (Hansen, 1992). $\boldsymbol{P}_{k_{-} S_{1}}, \boldsymbol{S}_{k_{-} s_{1}}$ are the identified parameters and the sensitivity matrix in the $\mathrm{k}^{\text {th }}$ iteration respectively. $\Delta \boldsymbol{P}_{k_{-} S_{1}}=\boldsymbol{P}_{k_{-} S_{1}}-\boldsymbol{P}_{k-1 S_{1}} . \boldsymbol{S}_{k-1_{-} S_{1}}$ is the sensitivity matrix in the $\mathrm{k}^{\text {th }}$ iteration with the structural model updated by the parameter in the previous iteration $\boldsymbol{P}_{k-1} s_{1}$.

The structural stiffness matrix is updated after $\Delta \boldsymbol{P}_{k_{-} s_{1}}$ is obtained. Then the structural responses and the sensitivity matrix can be re-calculated based on the updated stiffness matrix, and the vector $\Delta \boldsymbol{P}_{k_{-} s_{1}}$ for the next iteration is calculated until convergence is achieved with the following criterion as

$$
\frac{\left\|P_{k+1} S_{1}-P_{k_{-} S_{1}}\right\|}{\boldsymbol{P}_{k_{-} S_{1}}}<\text { Tol }
$$

The value of Tol is such selected to allow for the difficulty in the convergence of the identified results with noise effect.

The above procedure can be repeated for all scenarios of temperature variation, and the system parameter in all these scenarios can be obtained.

\section{Numerical studies}

\subsection{A finite element model of frame}

A two-dimensional frame structure as shown in Figure 5 with unknown rotational spring stiffnesses $\mathrm{K}_{2}, \mathrm{~K}_{3}, \mathrm{~K}_{5}$ and $\mathrm{K}_{6}$ and vertical compressive spring stiffnesses $\mathrm{K}_{1}$ and $\mathrm{K}_{4}$ is adopted for illustration. This structure is modelled using two planar beam finite elements with three internal nodes in the vertical component and three planar beam finite elements with 10 internal nodes in the horizontal component. The structure is simply-supported at column bases and sliding-hinged at both internal and external ends of beams. The cross-section of all beam members is $0.25 \mathrm{~m} \times 0.5 \mathrm{~m}$ and the that of column is a variable cross-section from $0.25 \mathrm{~m} \times 0.25 \mathrm{~m}$ to $0.4 \mathrm{~m} \times 0.4 \mathrm{~m}$. Beam and column members are of $4.150 \mathrm{~m}$ and $3.370 \mathrm{~m}$ long respectively. The material properties are assumed as the uniform along the length of the 
component. The mass density of material is $0.418 \mathrm{~g} / \mathrm{cm}^{3}$. The elastic modulus of material is $6435 \mathrm{MPa}$ around $20^{\circ} \mathrm{C}$ and the value of elastic modulus with temperature change can be found in Figure 6 (GBT 1928-2009). The Tibetan area is very dry and the moisture is very low in the building. The elastic modulus is considered as a contact with the small temperature change in this study. No external static loading is considered on the frame other than the self-weight of the structure. This configuration will be adopted for all studies in this paper.

The response data used for this study was generated from a numerical model in which a measured environmental temperature change history curve was applied. The response measurements include the strains at the beam and column as shown in Figure 7.

\subsection{Numerical simulations}

A uniform temperature change history curve with a maximum $30^{\circ} \mathrm{C}$ temperature difference is applied on the structure as shown in Figure 8. This data is based on the three-year field monitoring data of the heritage building in Tibet. 1096 data points are utilised in this simulation. The strain responses of the structure are calculated as the "measured" responses for the parameter identification. One strain measurement from the beam and another from column as shown in Figure 7 are used for the analysis. The temperature change history curve utilised here was obtained from field test data and it was catalogued into six scenarios: from $-15^{\circ} \mathrm{C}$ to $-10^{\circ} \mathrm{C}$, from $-10^{\circ} \mathrm{C}$ to $-5^{\circ} \mathrm{C}$, from $-5^{\circ} \mathrm{C}$ to $0^{\circ} \mathrm{C}$, from $0^{\circ} \mathrm{C}$ to $5^{\circ} \mathrm{C}$, from $5^{\circ} \mathrm{C}$ to $10^{\circ} \mathrm{C}$ and from $10^{\circ} \mathrm{C}$ to $15^{\circ} \mathrm{C}$, which are studied to check how the stiffness of 'Que-Ti' changes with temperature.

The stiffness parameters to be estimated and their initial values for the simulation are listed in Table 1 (Cao et al. 2015, Leichti et al. 2000, Salgado, 2008 and GBT 1928-2009). The response sensitivity-based method is used to identify the stiffnesses $\mathrm{K}_{1}$ to $\mathrm{K}_{6}$ and the error of the identified results are computed from Eq. (12) as

$$
\text { Error }=\frac{\left|K_{\text {identified }}-K_{\text {real }}\right|}{K_{\text {real }}} \times 100 \%
$$

where $K_{\text {real }}$ is the true value of the stiffness and $K_{\text {identified }}$ is the identified stiffness. This configuration of parameters and setting will be adopted for all the studies in this paper unless otherwise shown.

4.3 Identified results with or without measurement noise 
The effectiveness of the proposed method is studied with the "measured" responses without noise, and the convergence criterion $T o l$ is set as $10^{-9}$ in this case. The identification results from the proposed method are shown in Table 2. The identified results are very close to the true values. The results show that parameters of the semi-rigid connection can be identified accurately from measurements without noise.

In order to study the effectiveness of the proposed method in practice, the noisy "measured" response $\boldsymbol{\varepsilon}_{\text {meas }}$ is simulated by adding random noise to the calculated response as

$$
\boldsymbol{\varepsilon}_{\text {meas }}=\boldsymbol{\varepsilon}_{\text {cal }}+E_{p} \sigma\left(\boldsymbol{\varepsilon}_{\text {cal }}\right) \boldsymbol{N}_{\text {noise }}
$$

where $\boldsymbol{\varepsilon}_{c a l}$ is the calculated response; $\mathrm{E}_{\mathrm{p}}$ is the noise level; $\sigma\left(\boldsymbol{\varepsilon}_{c a l}\right)$ is the standard deviation of the unpolluted strain response and $\boldsymbol{N}_{\text {noise }}$ is a standard normally distributed vector with zero mean and unit standard deviation.

$10 \%$ noise level is added to simulate response measurements and the proposed method is used to identify the parameters of the semi-rigid connection. The convergence tolerance is set as $10^{-5}$. The identification results shown in Table 2 agree well with the true values even from measurements with $10 \%$ noise.

\subsection{Parametric analysis}

Since the focus of the proposed approach is the modeling of the temperature variations as a measurable forcing function for the structure to obtain a complete input-output relationship (Yarnold et al. 2015), it is necessary to know the limits of application of this approach for practical use, i.e. the initial value setting, the length of measured data and the sensor placement, etc. All these factors characterize the efficiency and accuracy of the proposed approach.

\section{(a) Effect of the initial values}

The stiffness values in the FEM are adopted from the summarized results of semi-rigid connection tests (Qin and Yang, 2018). Since the accuracy of the identified results based on the proposed sensitivity analysis would be affected by the initial value, three trials with different initial values are selected in the analysis, i.e. $90 \%, 80 \%$ and $50 \%$ of the true stiffness value in the FEM. As shown in Table 3, the identified results with the cases with initial values equal to $90 \%$ and $80 \%$ of the true value are accurate with less than $8.90 \%$ error. Those results from the former is more accurate than the results from the latter as noted in Table 3. However, 
the identification with the third trial of initial value is not good and the criterion Tol of the identification cannot be achieved after more than 500 iterations. In real application, a simplified analytical model, such as the two-layer wooden beam model by Cao et al. (2015) or an experimental joint model with the new wooden material can be used to determine the initial value.

(b) Effect of the data length

Three different length of data are selected in this study, i.e. 1096 (one data points selected per day), 2192 (two data points selected per day) and 3288 (three data points selected per day) data points, as shown in Figure 9. Table 4 shows the errors in the identified results. It is noted that there is no big difference in the results and the error is slightly reduced with the number of data points. Based on above, 1096 data points are used in the following study.

(c) Sensor placements

Figure 10 shows four different sensor arrangements as Scenarios I, II, III and IV. Scenario I is the full sensor placement scenario with five sensors and other scenarios have only two sensors. The errors of identification are obtained with 1096 data points and the results from Scenario I are much less than those from other three scenarios. There is no big difference in the results when the two sensors are arranged either in the middle span of the beam, column or on the one side of the structure (Lyu et al. 2017a).

\section{Experimental studies}

\subsection{Finite element model of a Tibetan heritage timber structure}

The Tibetan heritage timber structure is shown in Figure 11. It is an independent structural unit with full height walls on two opposite sides. The timber frame system between two walls is a longitudinal formed by columns and beams. As shown in Figure 1, the beam-column connection in the deep direction is very thin. It can be modelled numerically with a 3-storey two-dimensional frame (A-A in Figure 12). The details of the floor plan and the boundary conditions are shown in Figures 12 and 13, and the longitudinal boundary condition of the timber frame is treated as a semi-rigid connection with the longitudinal compressive stiffness only (Lyu et al. 2017a). It is assumed that there is no change in the mass and the damping when the temperature of the structure changes. The weight of adjacent floor slab and the roof is treated as additional mass added onto the frame structure. The floor and roof slabs are of $200 \mathrm{~mm}$ and $300 \mathrm{~mm}$ thickness respectively with density of material equals $20 \mathrm{kN} / \mathrm{m}^{3}$. 
A finite element model is developed and it includes 24 planar beam finite elements with three internal nodes in the vertical component and 27 planar beam finite elements with 10 internal nodes in the horizontal component, 48 rotational spring elements and 24 vertical spring elements for modeling the 'Que-Ti' and six longitudinal spring elements for modeling longitudinal boundary conditions of the timber frame, as shown in Figure 14. The temperature load is the only external load acting on the structure.

\subsection{Data acquisition system}

According to the on-site measurement of the frame, the strain data was collected at ten points in the frame, as shown in Figure 15. The Fiber Bragg grating strain gauge (FBG), as shown in Figure 16, is from China Orient Institute of Noise and Vibration. The model of the data acquisition system is BGK-FBG-8600 with 16 channels, as shown in Figure 17. The measuring duration lasts for 24 hours per day and the data is collected once per hour with the average of six measurements by $10 \mathrm{~min}$ each. Over three years monitoring data are available from the traditional building monitoring system, which provides a most unique database to evaluate the proposed approach.

\subsection{Data processing and interpretation}

Before using the data for model updating, it is important to check if the measured data adequately characterize the temperature-induced input-output relationships. Both the strain and temperature information are obtained with the FBG strain gauge and the data is noted change periodically. The record of three continuous days has been selected in this study. Taking the data from one sensor for example, the strain history curve and temperature history curve are shown in Figure 18. The temperature variation curve was divided into six scenarios for separate identification studies, i.e. from $-15^{\circ} \mathrm{C}$ to $-10^{\circ} \mathrm{C}$, from $-10^{\circ} \mathrm{C}$ to $-5^{\circ} \mathrm{C}$, from $-5^{\circ} \mathrm{C}$ to $0^{\circ} \mathrm{C}$, from $0{ }^{\circ} \mathrm{C}$ to $5^{\circ} \mathrm{C}$, from $5^{\circ} \mathrm{C}$ to $10^{\circ} \mathrm{C}$ and from $10^{\circ} \mathrm{C}$ to $15^{\circ} \mathrm{C}$. The temperature variation is treated as a measured force function in this study and the input (temperature) -output (strains) relationship can be established as discussed earlier. These relationships are simulated numerically.

The model updating from temperature-based method is presented below. As an example, Figure 19 shows the identification results of four torsional, vertical and longitudinal spring elements for all scenarios. The relations between rotational stiffness of the connection and temperature in Figure 19(a) show a nonlinear downward trend which is consistent with timber physical and mechanical characteristics. With the temperature increase, it is noted that there is an obviously rise by the end of the stiffness downward trend in Figure 19(a). This phenomenon 
is caused by the increase of the contact area of the shear connector between beam and 'Que-Ti' (Cao et al. 2015). The timber expands with increasing thermal load and the shear connector will be subjected to longitudinal shear contributing to the load resistance of the 'Que-Ti'. The vertical compressive stiffness of the connection in Figure 19(b) does not change a lot with temperature variation. The relation between the longitudinal compressive stiffness of connection and temperature is shown in Figure 19(c). The rising temperature induces an increase of the longitudinal compressive stiffness.

The above results may show that when the temperature increases, the timber component expands and the contact surface area between the side beam and the wall increases with greater frictional force. Overall, the identified rotational stiffness is from $4189 \mathrm{kNm} / \mathrm{r}$ to $11147 \mathrm{kNm} / \mathrm{r}$. The identified vertical compressive stiffness is from $85731 \mathrm{kN} / \mathrm{m}$ to $130957 \mathrm{kN} / \mathrm{m}$ and the identified longitudinal compressive stiffness is from $25012 \mathrm{kN} / \mathrm{m}$ to $38604 \mathrm{kN} / \mathrm{m}$.

The accuracy of the identified parameters is also checked and compared with that from linear stiffness connection (Lyu et al. 2017a) to make sure the mechanical behaviours were modelled properly. The long-term monitoring data was divided into two groups according to the time: the first group was used for model updating and the second group was for model validation. The parameters are identified using the first group of data. The identified parameters are used to predict the strain measurements that are compared with the second group of measured data. As shown in Figure 20, four components were selected for this study from the side span column of the top floor, the side span column of the ground floor, the middle span beam (bottom) of the top floor and the the middle span beam (bottom) of the second floor.

The strains from the column are shown in Figures 21 (a) and 21 (b), indicating the predicted strains based on the nonlinear model are much closer to the measurement strains than that by the linear model. The strain from the beam are shown in Figures 21(c) and 21(d) and the results further confirm the above point. The errors of identified results are shown in Figure 22. The errors from the nonlinear model are all less than $10 \%$ with the column elements and $7 \%$ with the beam elements, which are much smaller than those from linear model where the errors are around $15 \%$ for column elements and 10\% for beam elements. All results above reflect that the predicted results based on the nonlinear model match the measured value greatly. The discrepancy was within $10 \%$ and therefore considered adequate.

\section{Conclusions}


A temperature-driven multimodel method is presented to identify the connection stiffnesses of the semi-rigid joint 'Que-Ti' in traditional Tibetan timber building. The nonlinear behaviour in timber buildings arising from ambient strain and temperature variation have been considered. Numerical and experimental results show that the proposed method is effective and reliable to predict the stiffness of the connection. The following specific conclusions and recommendations can be drawn from this study:

1) The numerical results show that the proposed method is robust to the measurement noise. The identified results agree well with the true values even with $10 \%$ noise in the measurement.

2) Six deformation scenarios on the range of temperature variation are selected for the nonlinear stiffness identification of the 'Que-Ti'. Sufficient data points are needed in the identification for better accuracy in the identification.

3) The proposed nonlinear connection model for the 'Que-Ti' can lead to a better accuracy in the identified results compared to that from a linear connection model.

\section{Acknowledgments}

The work described in this paper was supported by Key Projects in the National Science \& Technology Pillar Program during the Twelfth Five-year Plan Period (Grant 2015BAK01B02), Beijing Natural Science Foundation of China (Grant 8151003), National Natural Science Foundation of China Grant (51422801) and the 111 project of the Ministry of Education and the Bureau of Foreign Experts of China (No.B18062). The effort made by Prof. S.S. Law in improving the English of this paper is also gratefully acknowledged.

\section{References}

Adeniran, A.A. and El Ferik, S. Modeling and identification of nonlinear systems: a review of the multimodel approach-Part 1. IEEE Transactions on Systems, Man, and Cybernetics: Systems, 2017, 47(7): 1149-1159.

Aktan, A. E., Farhey, D. N., Helmicki, A. J., Brown, D. L., Hunt, V. J., Lee, K.L., and Levi, A. Structural Identification for Condition Assessment: Experimental Arts. Journal of Structural Engineering ASCE, 1997, 123(12): 1674-1684. 
Brownjohn, J., Moyo, P., Omenzetter, P., and Lu, Y. Assessment of highway bridge upgrading by dynamic testing and finite-element model updating. Journal of Bridge Engineering, ASCE, 2003, 8(3): 162-172.

Burdet, O. L. Thermal Effects in the Long-Term Monitoring of Bridges. Proc., IABSE Symposium on Large structures and Infrastructures for Environmentally Constrained and Urbanised Areas.

Cao, P.L., Yang Q.S., and Law, S.S. Nonlinear analytical model of a two-layer wooden beam in a heritage structure. Engineering Structures, 2015, 101: 494-508

Cao, Y., Yim, J., Zhao, Y., and Wang, M. L. Temperature effects on cable stayed bridge using health monitoring system: a case study. Structural Health Monitoring, 2011, 10(5): 523-537.

Catbas, F. N., and Aktan, A. E. Condition and Damage Assessment: Issues and Some Promising Indices. Journal of Structural Engineering ASCE, 2002, 128(8): 1026-1036.

Catbas, F. N., Susoy, M., and Frangopol, D. M. Structural health monitoring and reliability estimation: Long span truss bridge application with environmental monitoring data. Engineering Structures, 2008, 30(9): 2347-2359.

Cattarius, J. and Inman, D. J. Time domain analysis for damage detection in smart structures. Mechanical Systems ad Signal processing, 1997, 11(3): 409-423.

Dai, L., Yang, N., Zhang, L., Yang, Q.S. and Law, S.S. Monitoring crowd load effect on typical ancient Tibetan building. Structural Control and Health Montioring, 2016, 23(7): 998-1014.

De Stefano, A., Matta, E. and Clementre, P. Structural health monitoring of histrorical heritage in Italy: some relevant experiences. Journal of Civil Structural Health Montioring, 2016, 6(1): 83-106.

Fang, D. P., Iwasaki, S., Yu, M. H. and Shen, Q. P. Ancient Chinese timber architecture. II: dynamic characteristics. Journal of Structural Engineering, ASCE, 2001, 127(11): 1358-1364.

Koh, C. G., Hong, B. and Liaw, C. Y. Parameter identification of large structural systems in time domain. Journal of Structural Engineering, ASCE, 2000, 126(8): 957-963.

Kulprapha, N. and Warnitchai, P. Structrual health monitoring of continuous prestressed concrete bridges using ambient thermal responses. Engineering Structures, 2012, 40: 20-38.

Leichti, R. J., Hyde, R. A., French, M. L. and Camillos, S. G. The continuum of connection rigidity in timber structures. Wood and Fiber Science, 2000, 32(1): 11-19.

Link, M. and Weiland, M. Damage identification by multi-model updating in the modal and in the time domain. Mechanical Systems and Signal Processing, 2009, 23: 1734-1746.

Lu, Z. R. and Law, S. S. Features of dynamic response sensitivity and its application in damage detection. Journal of Sound and Vibration, 2007, 303: 305-329. 
Lu, Z. R. and awng, L. An enhanced response sensitivity approach for structural damage identification: convergence and perfromance. International Journal for Numerical Methods in Engineering, 2017, 111: 12311251.

Lyu, M.N., Zhu X.Q., and Yang Q.S. Connection stiffness identification of historic timber buildings using temperature-based sensitivity analysis. Engineering Structures, 2017a, 131: 180-191.

Lyu, M.N., Zhu, X.Q. and Yang, Q.S. Bilinear connection stiffness identification of heritage timber buildings with limited strain measurements. Engineering Structures, 2017b, 151: 665-681.

National standard of the People's Republic of China. General requirements for physical and mechanical tests of wood (GBT 1928-2009). General Administration of Quality Supervision, Inspection and Quarantine. 2009.

Qin, S.J. and Yang, N. Strength degradation and service life prediction of timber in ancient Tibetan building. European Journal of Wood and Wood Products, 2018, 76(2): 731-747.

Riggio, M. and Dilmaghani, M. Structural health monitoring of timber buildings: a literature survey. Building Research \& Information, 2019, 1681253.

Salgado R. The Engineering of Foundations, McGraw-Hill, New York, 2008.

The ministry of construction of the People's Republic of China. Code for Design of Timber Structures (GB 500052003). Beijing: China Building Industry Press, 2003.

Wang, J., He, J.X., Yang, N. and Yang, Q.S. Study on aseismic characteristics of Tibetan ancient timber structure. Advances in Materials Science and Engineering, 2017, ID 8186768.

Wei, J.J. and Lv, Z.R. Structural damage detection including the temperature difference based on response sensitivity analysis. Structural Engineering and Mechanics, 2015, 53(2): 249-260.

Xie, Q.F., Wang, L., Zheng, P.J., Zhang, L.P. and Hu, W.B. Rotational behaviour of degraded traditional mortisetenon joints: experimental tests and hysteretic model. International Journal of Architectural Heritage, 2018, 12(1): 125-136.

Yarnold, M.T. and Moon, F.L. Temperature-based structural health monitoring baseline for long-span bridges. Engineering Structures, 2015, 86: 157-167.

Yarnold, M. T., Moon, F. L. and Aktan, A. E. Temperature-Based Structural Identification of Long-Span Bridges. Journal of Structural Engineering, ASCE, 2015, 04015027-1

Yuen, K.V. and Kuok, S.C. Ambient interference in long-term monitoring of buildings. Engineering Structures, 2010, 32(8): 2379-2386.

Yuan, P.-P., Ren, W.-X. and Zhang, J. Dynamic tests and model updating of nonlinear beam structures with bolted joints. Mechanical Systems and Signal Processing, 2019, 126: 193-210. 
Table 1 - The stiffness parameter values for simulation

\begin{tabular}{|c|c|c|c|c|c|c|c|}
\hline & & Scenario 1 & Scenario 2 & Scenario 3 & Scenario 4 & Scenario 5 & Scenario 6 \\
\hline \multirow{2}{*}{$\begin{array}{c}\mathrm{K}_{1} \\
(\mathrm{kN} / \mathrm{m})\end{array}$} & Ideal value & $1.19 \times 10^{5}$ & $1.16 \times 10^{5}$ & $1.13 \times 10^{5}$ & $1.08 \times 10^{5}$ & $1.05 \times 10^{5}$ & $1.01 \times 10^{5}$ \\
\hline & $\begin{array}{l}\text { Initial } \\
\text { value }\end{array}$ & $1.0 \times 10^{5}$ & $1.0 \times 10^{5}$ & $1.0 \times 10^{5}$ & $1.0 \times 10^{5}$ & $1.0 \times 10^{5}$ & $1.0 \times 10^{5}$ \\
\hline \multirow{2}{*}{$\begin{array}{c}\mathrm{K}_{2} \\
(\mathrm{kNm} / \mathrm{r})\end{array}$} & Ideal value & 8460 & 8280 & 8020 & 7700 & 7475 & 7200 \\
\hline & $\begin{array}{l}\text { Initial } \\
\text { value }\end{array}$ & 7000 & 7000 & 7000 & 7000 & 7000 & 7000 \\
\hline \multirow{2}{*}{$\begin{array}{c}\mathrm{K}_{3} \\
(\mathrm{kNm} / \mathrm{r})\end{array}$} & Ideal value & 6925 & 6775 & 6565 & 6300 & 6115 & 5890 \\
\hline & $\begin{array}{l}\text { Initial } \\
\text { value }\end{array}$ & 7000 & 7000 & 7000 & 7000 & 7000 & 7000 \\
\hline \multirow{2}{*}{$\begin{array}{c}\mathrm{K}_{4} \\
(\mathrm{kN} / \mathrm{m})\end{array}$} & Ideal value & $1.01 \times 10^{5}$ & $0.99 \times 10^{5}$ & $0.96 \times 10^{5}$ & $0.92 \times 10^{5}$ & $0.9 \times 10^{5}$ & $0.86 \times 10^{5}$ \\
\hline & $\begin{array}{l}\text { Initial } \\
\text { value }\end{array}$ & $1.0 \times 10^{5}$ & $1.0 \times 10^{5}$ & $1.0 \times 10^{5}$ & $1.0 \times 10^{5}$ & $1.0 \times 10^{5}$ & $1.0 \times 10^{5}$ \\
\hline \multirow{2}{*}{$\begin{array}{c}\mathrm{K}_{5} \\
(\mathrm{kNm} / \mathrm{r})\end{array}$} & Ideal value & 8155 & 8000 & 7730 & 7420 & 7200 & 6950 \\
\hline & $\begin{array}{l}\text { Initial } \\
\text { value }\end{array}$ & 7000 & 7000 & 7000 & 7000 & 7000 & 7000 \\
\hline \multirow{2}{*}{$\begin{array}{c}\mathrm{K}_{6} \\
(\mathrm{kNm} / \mathrm{r})\end{array}$} & Ideal value & 7230 & 7075 & 6855 & 6580 & 6390 & 6150 \\
\hline & $\begin{array}{l}\text { Initial } \\
\text { value }\end{array}$ & 7000 & 7000 & 7000 & 7000 & 7000 & 7000 \\
\hline
\end{tabular}


Table 2 -Errors (\%) in the parameter identification result

\begin{tabular}{cccccccc}
\hline & & Scenario 1 & Scenario 2 & Scenario 3 & Scenario 4 & Scenario 5 & Scenario 6 \\
\hline \multirow{3}{*}{ Without } & $\mathrm{K}_{1}$ & 0.44 & 0.28 & 0.25 & 0.16 & 0.22 & 0.21 \\
\cline { 2 - 8 } noise & $\mathrm{K}_{2}$ & 0.37 & 0.41 & 0.17 & 0.15 & 0.24 & 0.09 \\
\cline { 2 - 8 } & $\mathrm{K}_{3}$ & 0.29 & 0.35 & 0.44 & 0.21 & 0.22 & 0.28 \\
\cline { 2 - 8 } & $\mathrm{K}_{4}$ & 0.33 & 0.31 & 0.54 & 0.23 & 0.21 & 0.15 \\
\cline { 2 - 8 } & $\mathrm{K}_{5}$ & 0.27 & 0.41 & 0.33 & 0.30 & 0.29 & 0.34 \\
\cline { 2 - 8 } & $\mathrm{K}_{6}$ & 0.54 & 0.31 & 0.27 & 0.22 & 0.20 & 0.20 \\
\cline { 2 - 8 } $10 \%$ & $\mathrm{~K}_{1}$ & 6.17 & 4.28 & 6.22 & 5.26 & 5.89 & 7.11 \\
\cline { 2 - 8 } noise & $\mathrm{K}_{2}$ & 7.53 & 5.31 & 4.77 & 5.98 & 6.64 & 5.75 \\
\cline { 2 - 8 } & $\mathrm{K}_{3}$ & 4.64 & 6.21 & 6.56 & 7.01 & 7.27 & 6.54 \\
\cline { 2 - 8 } & $\mathrm{K}_{4}$ & 7.16 & 7.03 & 6.18 & 6.98 & 7.25 & 5.74 \\
\cline { 2 - 8 } & $\mathrm{K}_{5}$ & 8.11 & 7.89 & 6.36 & 8.56 & 7.90 & 4.66 \\
\hline
\end{tabular}


Table 3 - Errors (\%) in the identification results with different initial values

\begin{tabular}{|c|c|c|c|c|c|c|c|}
\hline & & Scenario 1 & Scenario 2 & Scenario 3 & Scenario 4 & Scenario 5 & Scenario 6 \\
\hline \multirow{6}{*}{$\begin{array}{l}90 \% \\
\text { initial } \\
\text { value }\end{array}$} & $\mathrm{K}_{1}$ & 6.05 & 4.20 & 6.10 & 5.16 & 5.78 & 6.97 \\
\hline & $\mathrm{K}_{2}$ & 6.47 & 4.57 & 4.10 & 5.14 & 5.71 & 4.94 \\
\hline & $\mathrm{K}_{3}$ & 3.73 & 5.00 & 5.28 & 5.64 & 5.85 & 5.26 \\
\hline & $\mathrm{K}_{4}$ & 6.23 & 6.12 & 5.38 & 6.07 & 6.31 & 4.99 \\
\hline & $\mathrm{K}_{5}$ & 7.99 & 7.78 & 6.27 & 8.44 & 7.79 & 4.59 \\
\hline & $\mathrm{K}_{6}$ & 5.69 & 4.89 & 6.73 & 6.51 & 5.23 & 6.42 \\
\hline \multirow{6}{*}{$\begin{array}{c}80 \% \\
\text { initial } \\
\text { value }\end{array}$} & $\mathrm{K}_{1}$ & 6.58 & 4.57 & 6.64 & 5.61 & 6.29 & 7.59 \\
\hline & $\mathrm{K}_{2}$ & 7.98 & 5.62 & 5.05 & 6.33 & 7.03 & 6.09 \\
\hline & $\mathrm{K}_{3}$ & 4.98 & 6.67 & 7.04 & 7.53 & 7.81 & 7.02 \\
\hline & $\mathrm{K}_{4}$ & 7.55 & 7.42 & 6.52 & 7.36 & 7.65 & 6.06 \\
\hline & $\mathrm{K}_{5}$ & 8.36 & 8.13 & 6.56 & 8.82 & 8.14 & 4.80 \\
\hline & $\mathrm{K}_{6}$ & 7.16 & 6.16 & 8.47 & 8.20 & 6.58 & 8.08 \\
\hline
\end{tabular}

Table 4 - Errors (\%) in the parameter identification results with different data points

\begin{tabular}{|c|c|c|c|c|c|c|c|}
\hline & & Scenario 1 & Scenario 2 & Scenario 3 & Scenario 4 & Scenario 5 & Scenario 6 \\
\hline \multirow{6}{*}{$\begin{array}{l}1096- \\
\text { point } \\
\text { data }\end{array}$} & $\mathrm{K}_{1}$ & 6.17 & 4.28 & 6.22 & 5.26 & 5.89 & 7.11 \\
\hline & $\mathrm{K}_{2}$ & 7.53 & 5.31 & 4.77 & 5.98 & 6.64 & 5.75 \\
\hline & $\mathrm{K}_{3}$ & 4.64 & 6.21 & 6.56 & 7.01 & 7.27 & 6.54 \\
\hline & $\mathrm{K}_{4}$ & 7.16 & 7.03 & 6.18 & 6.98 & 7.25 & 5.74 \\
\hline & $\mathrm{K}_{5}$ & 8.11 & 7.89 & 6.36 & 8.56 & 7.90 & 4.66 \\
\hline & $\mathrm{K}_{6}$ & 6.78 & 5.83 & 8.02 & 7.76 & 6.23 & 7.65 \\
\hline \multirow{6}{*}{$\begin{array}{c}2192- \\
\text { point } \\
\text { data }\end{array}$} & $\mathrm{K}_{1}$ & 5.72 & 3.97 & 5.76 & 4.87 & 5.46 & 6.59 \\
\hline & $\mathrm{K}_{2}$ & 7.37 & 5.20 & 4.67 & 5.86 & 6.50 & 5.63 \\
\hline & $\mathrm{K}_{3}$ & 4.47 & 5.99 & 6.32 & 6.76 & 7.01 & 6.31 \\
\hline & $\mathrm{K}_{4}$ & 6.98 & 6.86 & 6.03 & 6.81 & 7.07 & 5.60 \\
\hline & $\mathrm{K}_{5}$ & 7.91 & 7.69 & 6.20 & 8.34 & 7.70 & 4.54 \\
\hline & $\mathrm{K}_{6}$ & 6.46 & 5.56 & 7.64 & 7.40 & 5.94 & 7.29 \\
\hline \multirow{6}{*}{$\begin{array}{c}3288- \\
\text { point } \\
\text { data }\end{array}$} & $\mathrm{K}_{1}$ & 5.45 & 3.78 & 5.50 & 4.65 & 5.20 & 6.28 \\
\hline & $\mathrm{K}_{2}$ & 7.47 & 5.27 & 4.73 & 5.93 & 6.59 & 5.71 \\
\hline & $\mathrm{K}_{3}$ & 4.17 & 5.58 & 5.90 & 6.30 & 6.53 & 5.88 \\
\hline & $\mathrm{K}_{4}$ & 6.90 & 6.77 & 5.95 & 6.72 & 6.98 & 5.53 \\
\hline & $\mathrm{K}_{5}$ & 7.32 & 7.13 & 5.74 & 7.73 & 7.13 & 4.21 \\
\hline & $\mathrm{K}_{6}$ & 6.41 & 5.51 & 7.58 & 7.34 & 5.89 & 7.23 \\
\hline
\end{tabular}



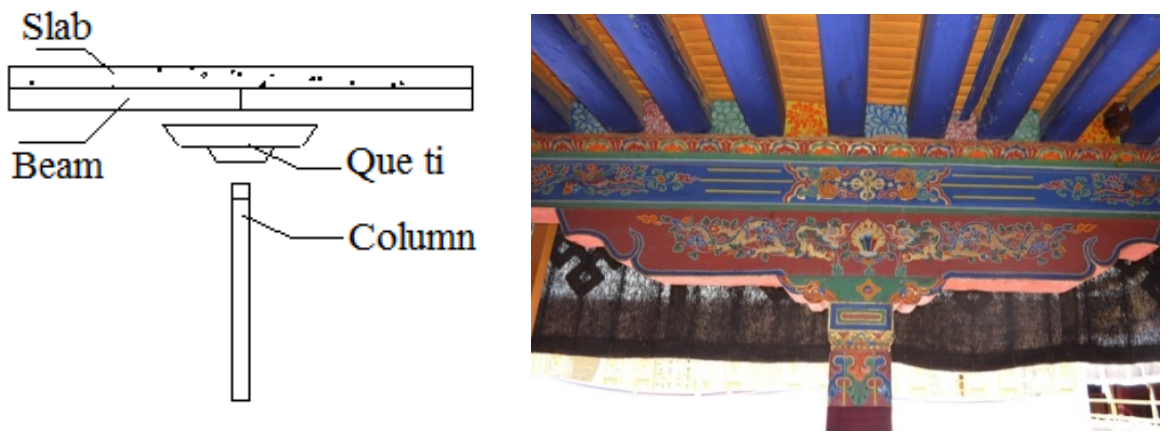

Figure 1 Composition of beam-column joints

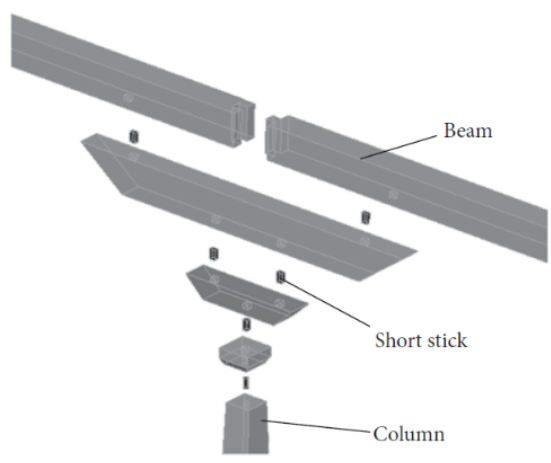

(a) Inner connections between joint components

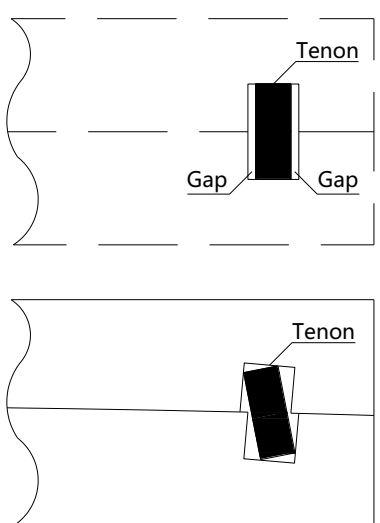

(b) The gap between the tenon and mortise

Figure 2 The tenon and mortise of 'Que-Ti'

Semirigid Connection Element

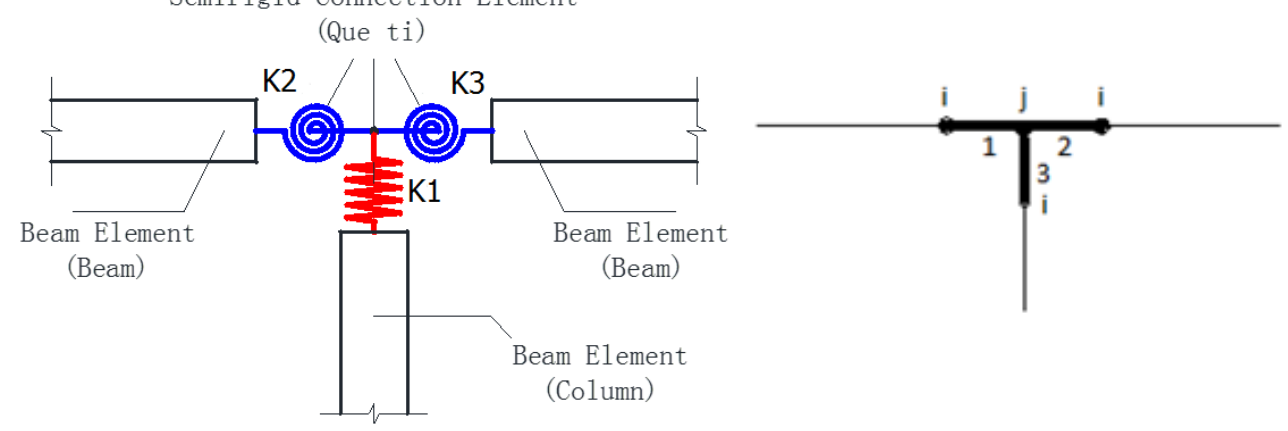

Figure 3 Simplified model of the beam-column connection 


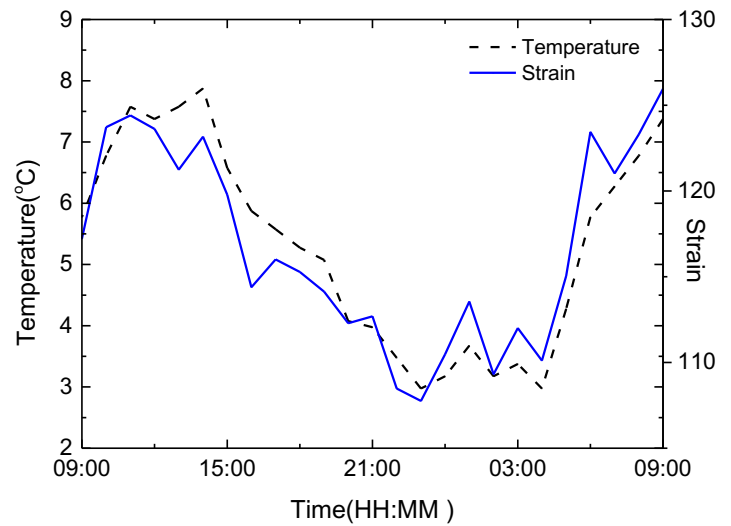

(a) Strain and temperature on the beam over 1 day

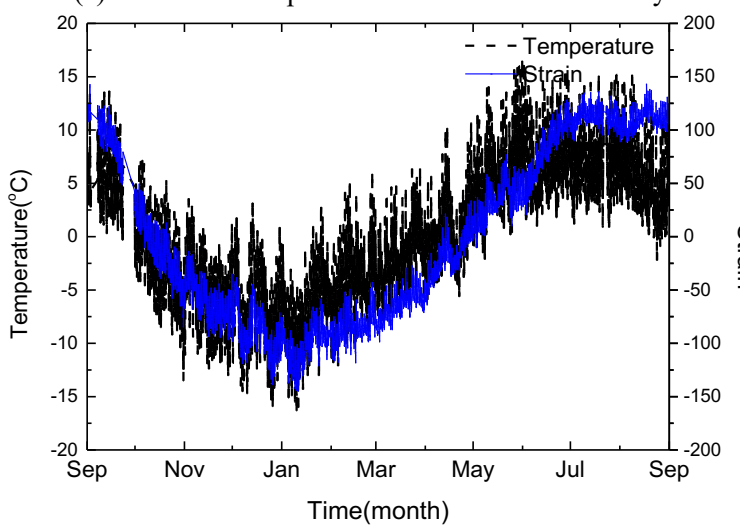

(c) Strain and temperature on the beam over 1 year

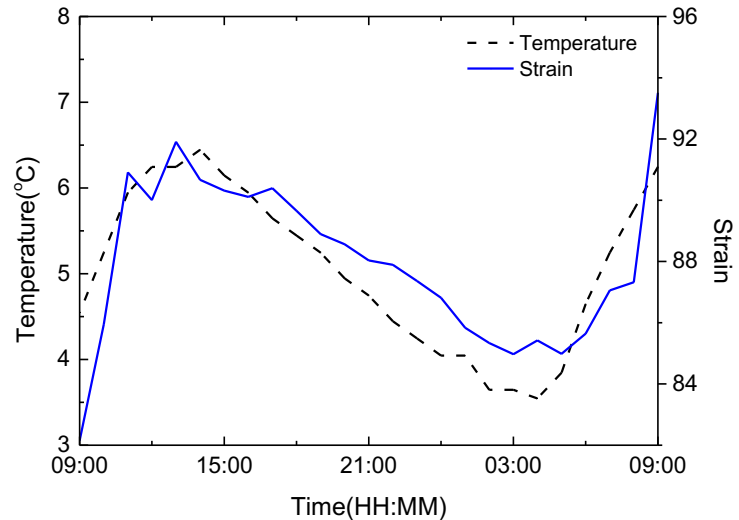

(b) Strain and temperature on the column over 1 day

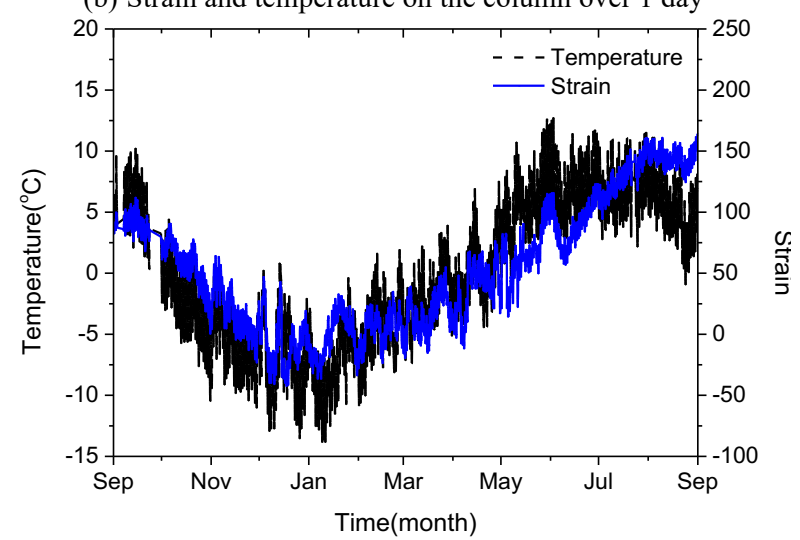

(d) Strain and temperature on the column over 1 year



(e) The nonlinear relationship of temperature versus strain response

Figure 4 Plot of measurements of strain from the ancient building in relation to ambient temperature 


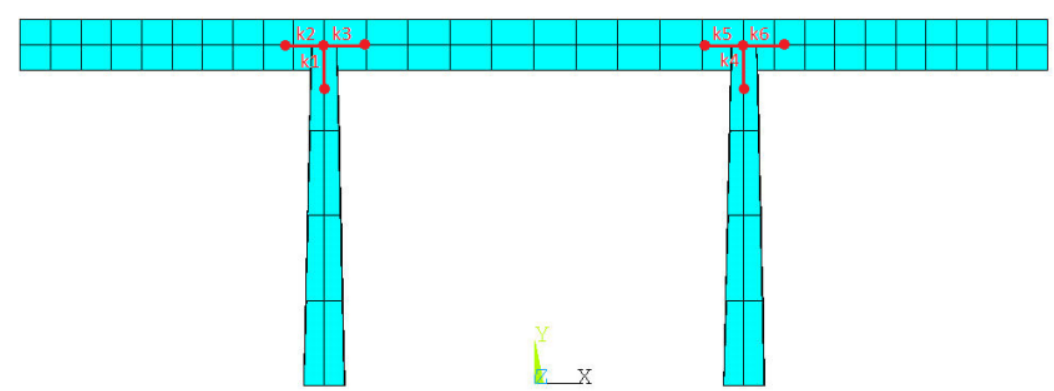

Figure 5 A two dimensional frame structure

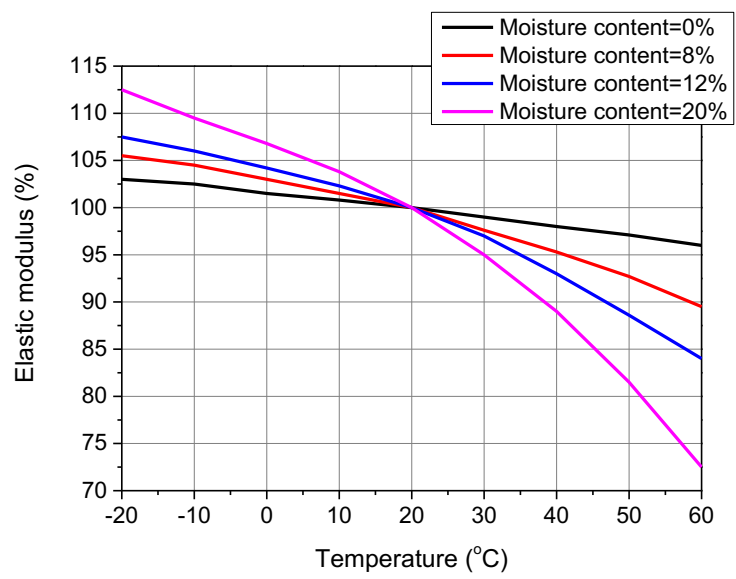

Figure 6 The relation between elastic modulus of timber and temperature



Figure 7 Sensor arrangement

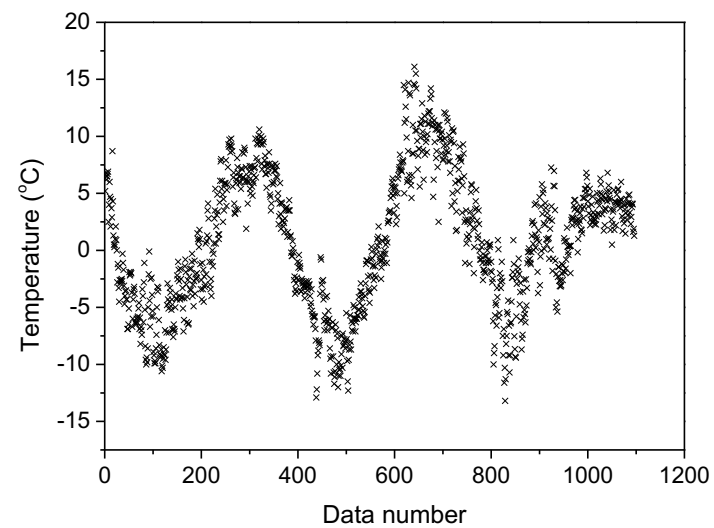

Figure 8 Temperature applied on structure 


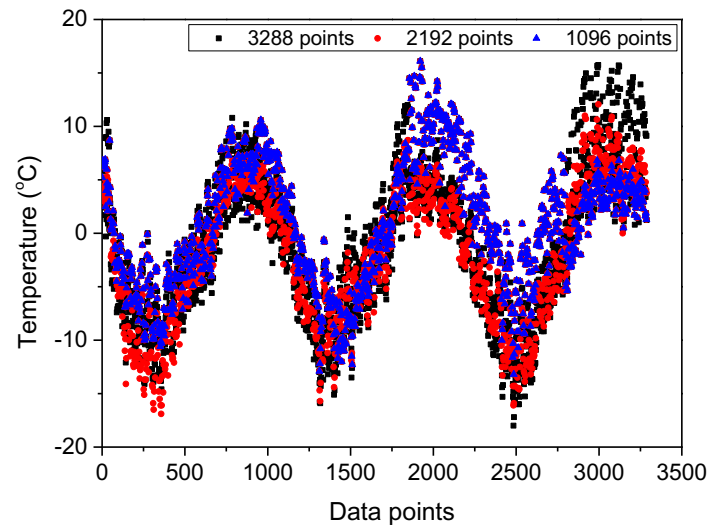

Figure 9 Three different temperature data points

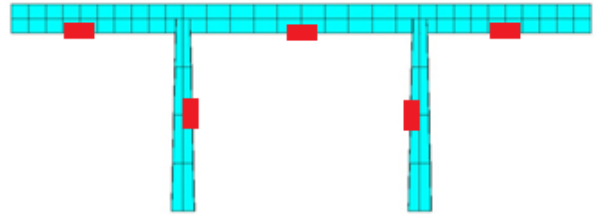

Scenario I

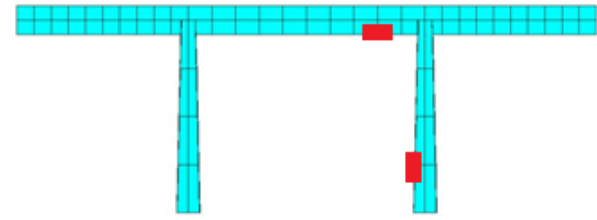

Scenario III

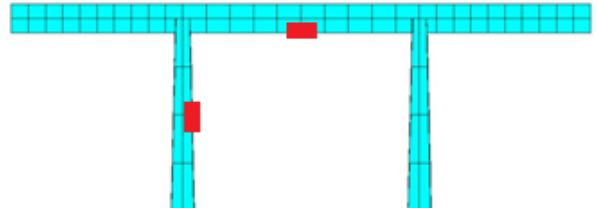

Scenario II

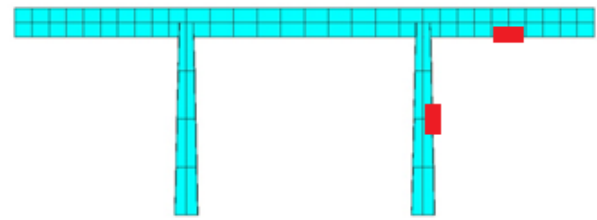

Scenario IV

Figure 10 Different sensor arrangements

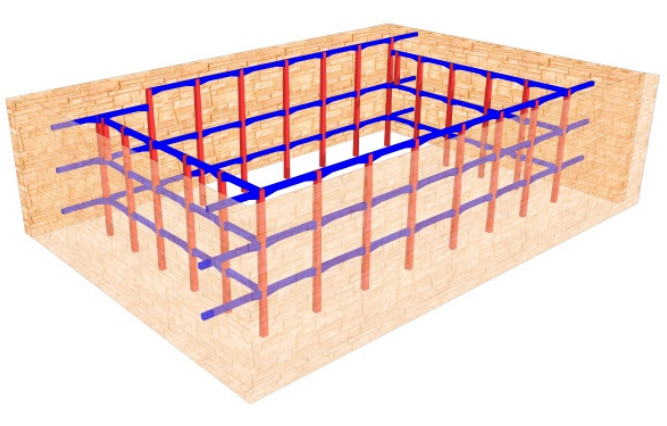

Figure 11 The traditional Chinese timber building

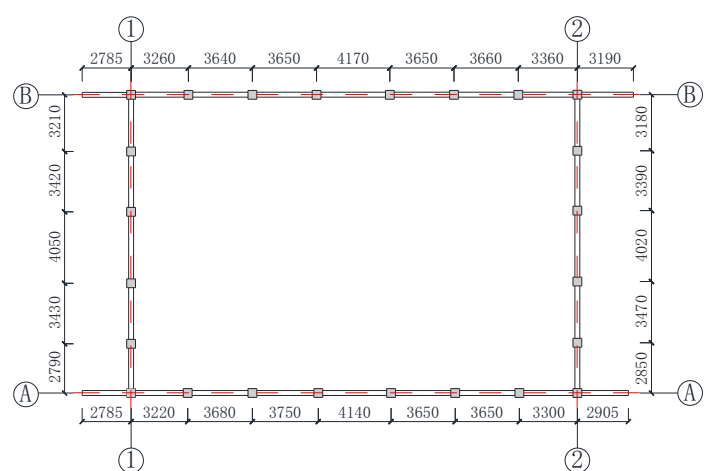

Figure 12 Floor plan for the three-storey wooden frame 


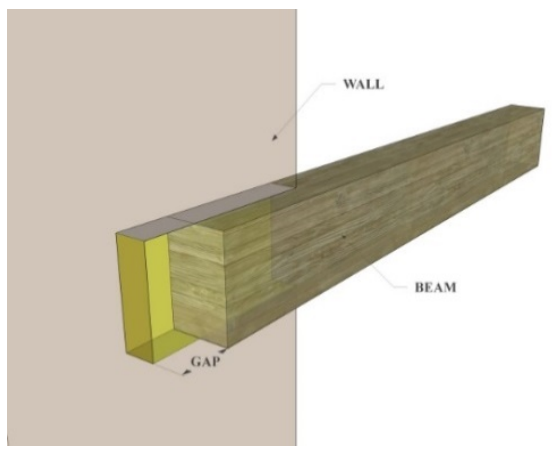

Figure 13 The boundary conditions of the heritage building

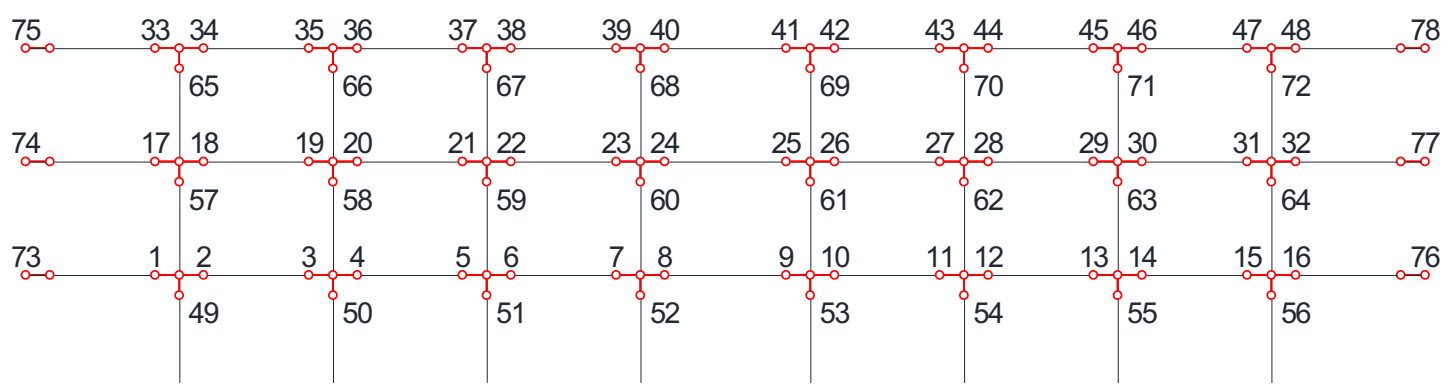

Figure 14 The frame structure with the spring element number

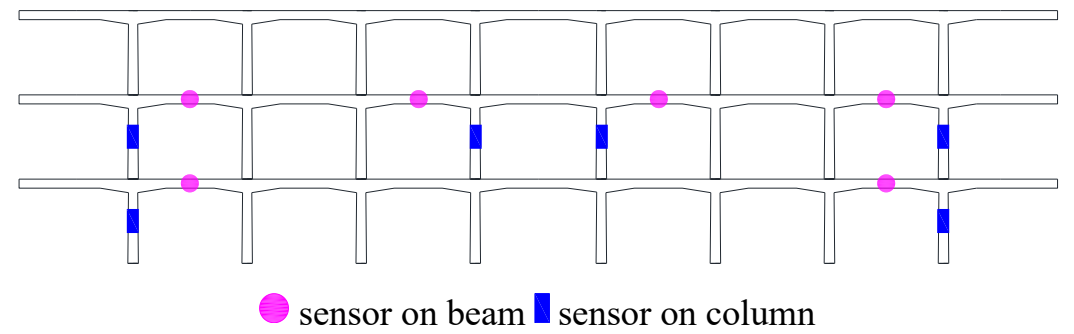

Figure 15 The frame model and sensor arrangement
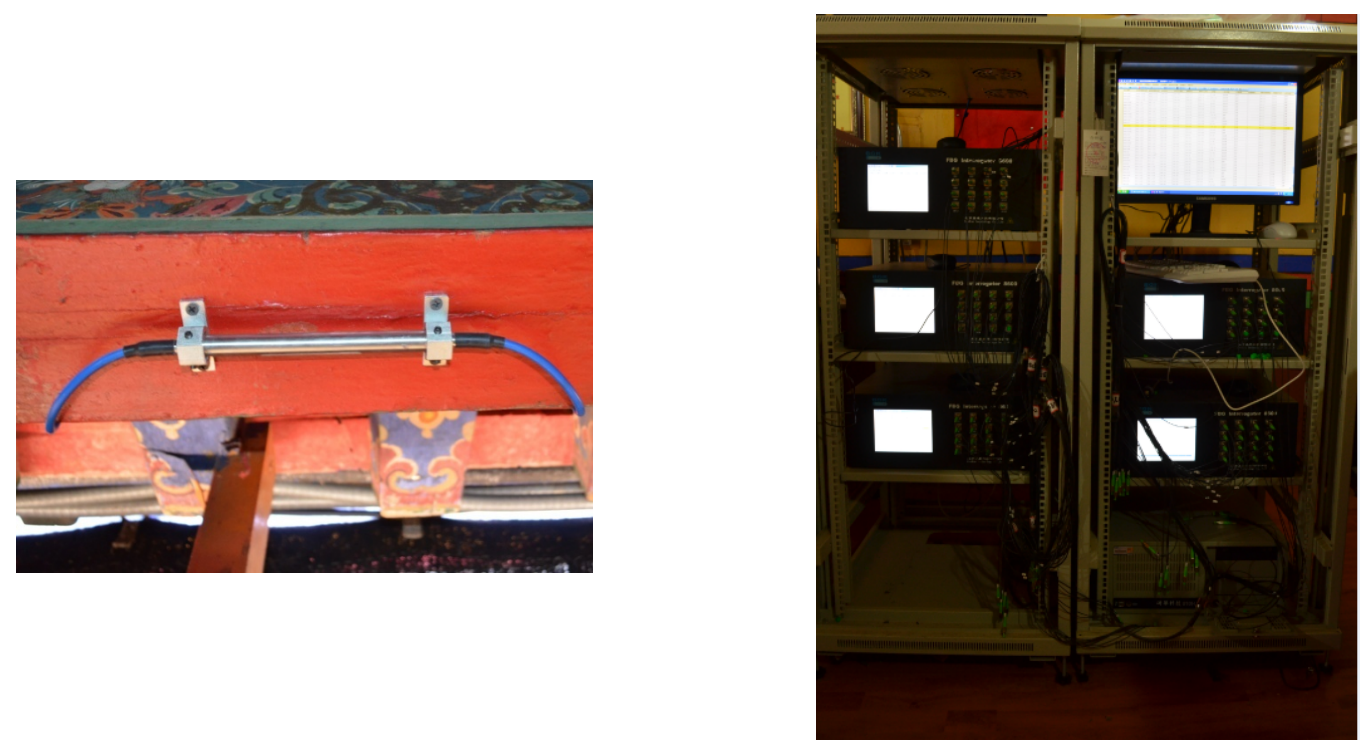

Figure 16 The Fiber Bragg grating strain gauge

Figure 17 The data acquisition system 


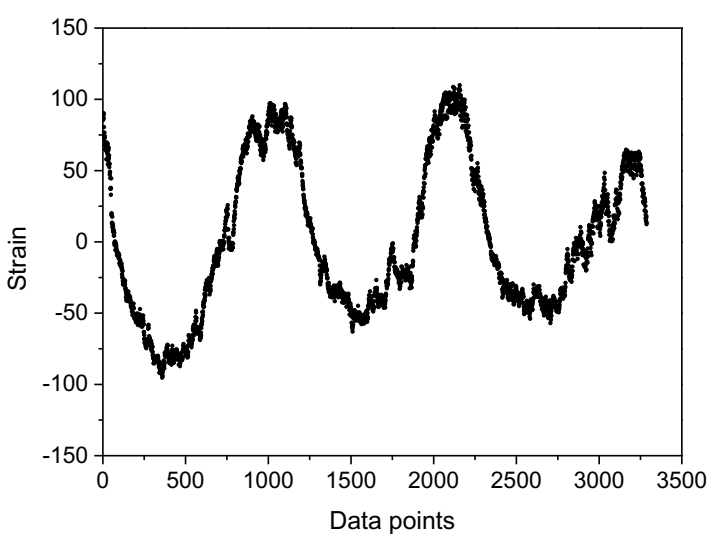

(a) Strain time history

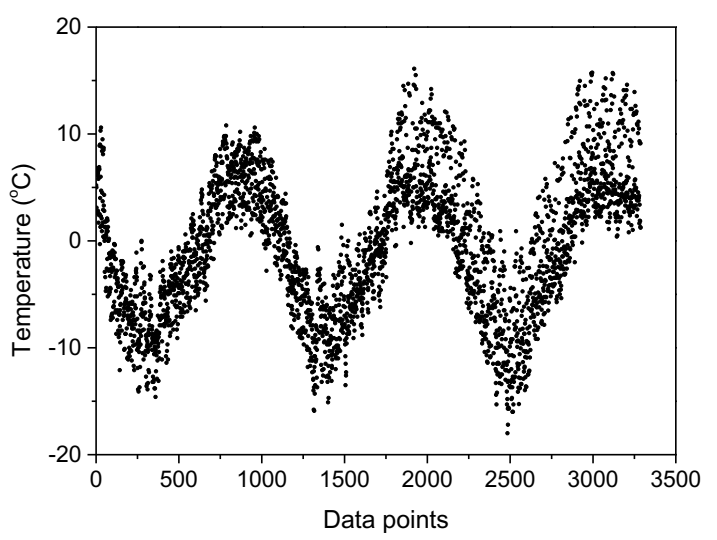

(b) Temperature changes

Figure 18 Data from Fiber Bragg grating strain gauges

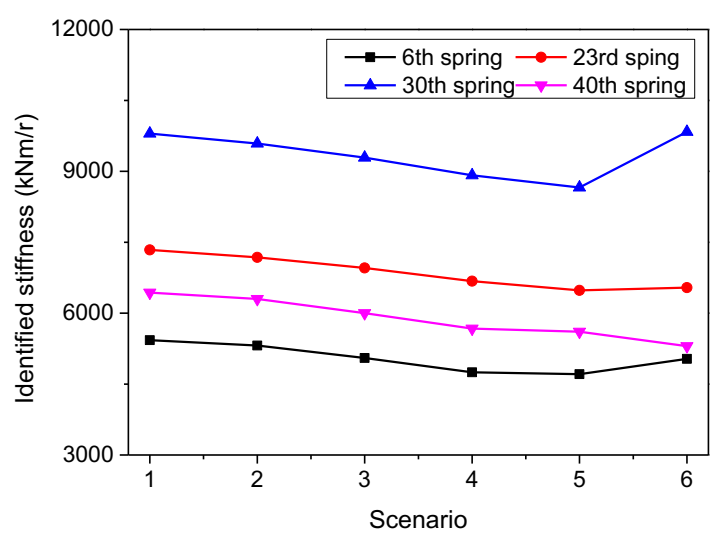

(a) The results of rotational spring elements

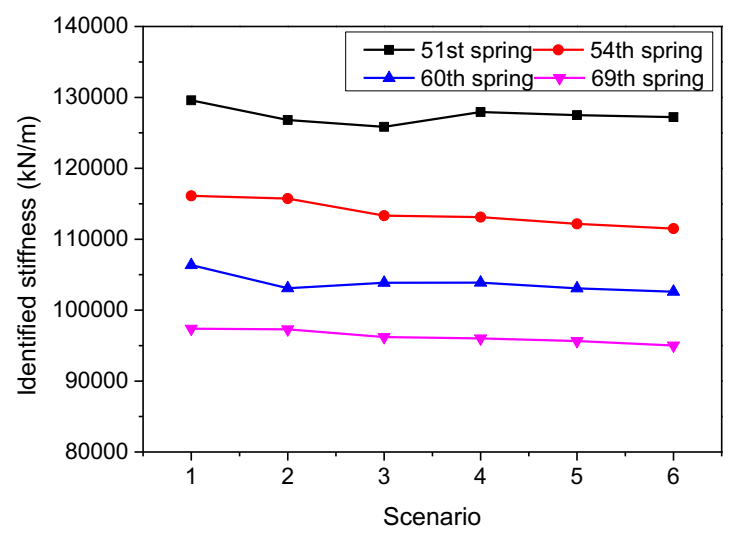

(b) The results of vertical spring elements

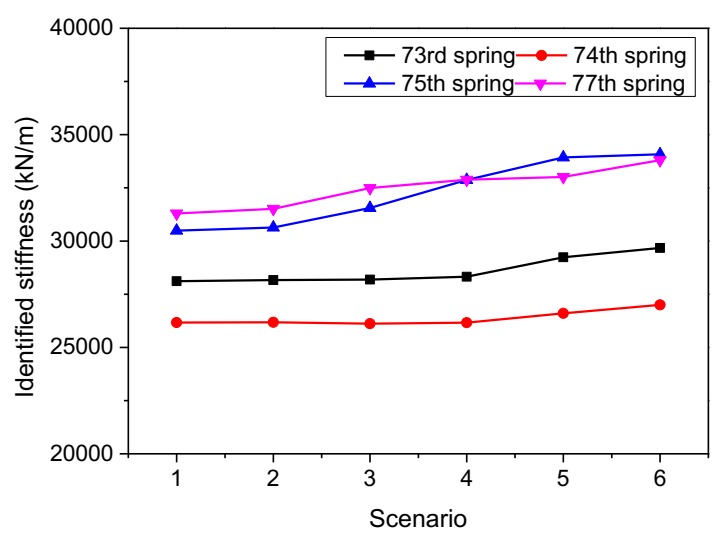

(c) The results of longitudinal spring elements

Figure 19 The identified stiffness results of spring elements 

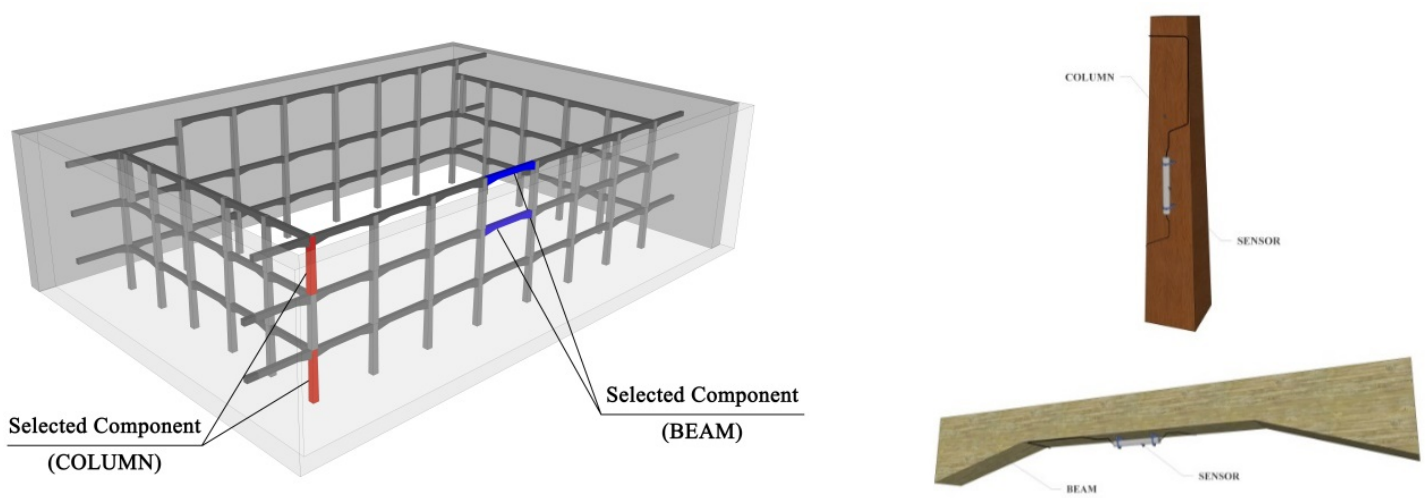

Figure 20 The selected components for comparison



(a) Site on side span column of the top floor

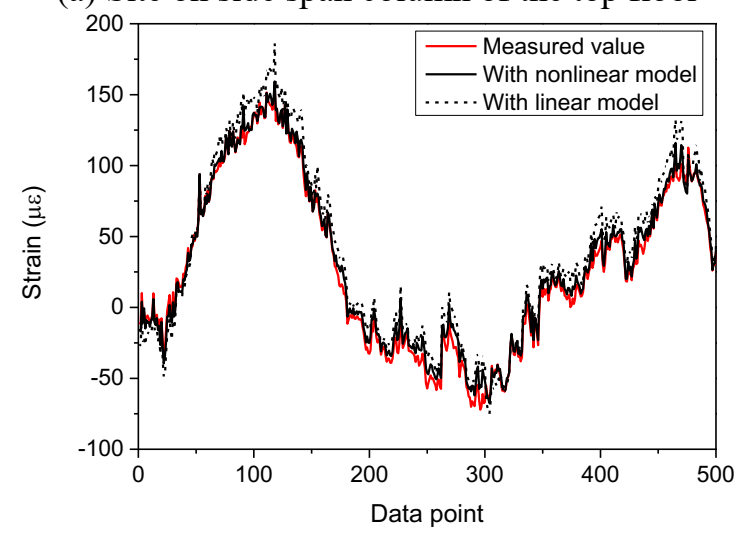

(c) Site on middle span beam of the top floor

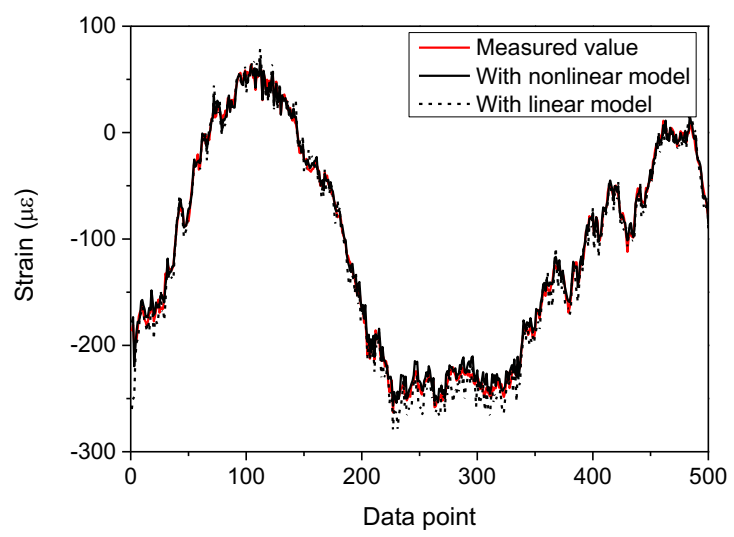

(b) Site on side span column of the ground floor

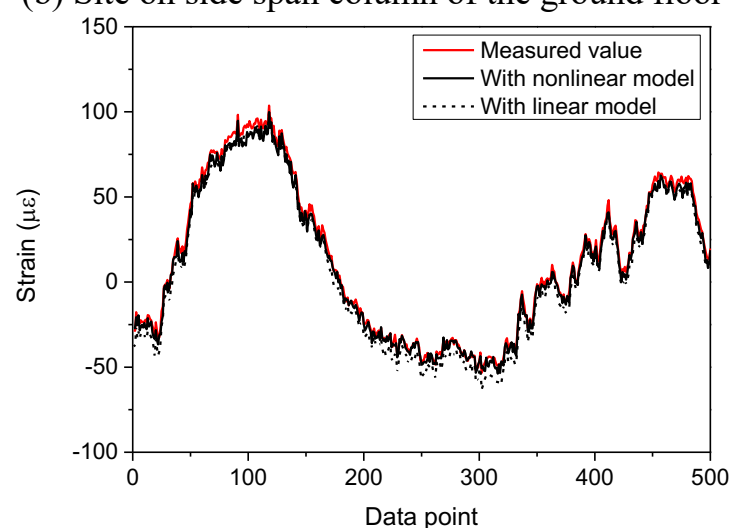

(d) Site on the middle span beam of the 2nd floor Figure 21 Calculated results of strain history curves compared with measured data 


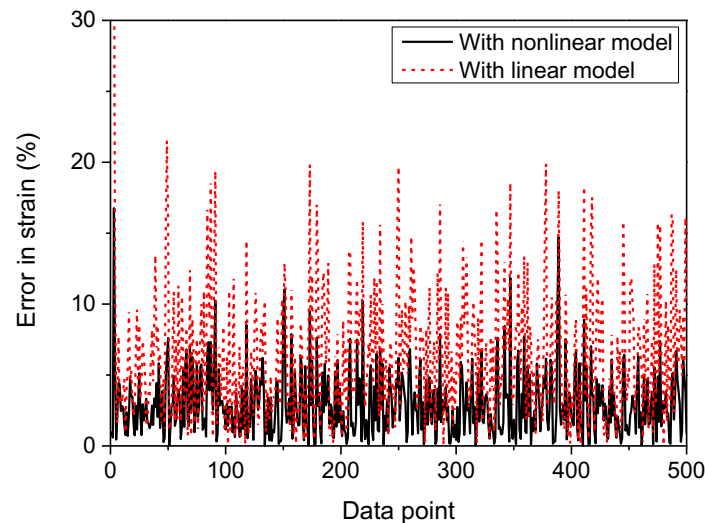

(a) Site at side span column on the top floor

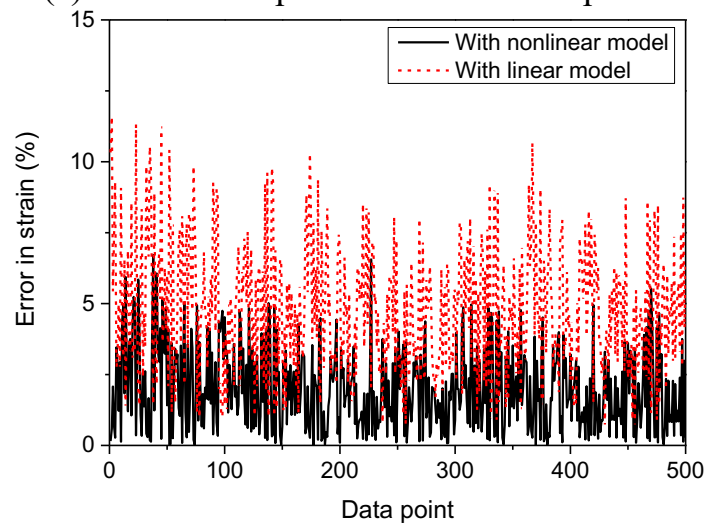

(c) Site at middle span beam on the top floor

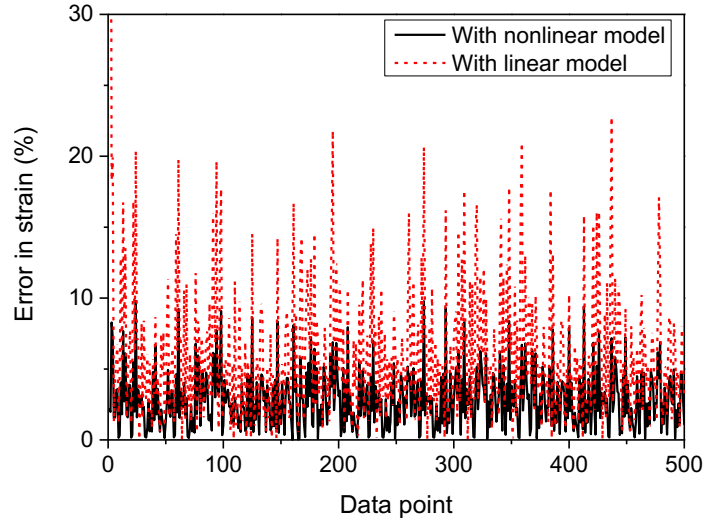

(b) Site at side span column on the ground floor

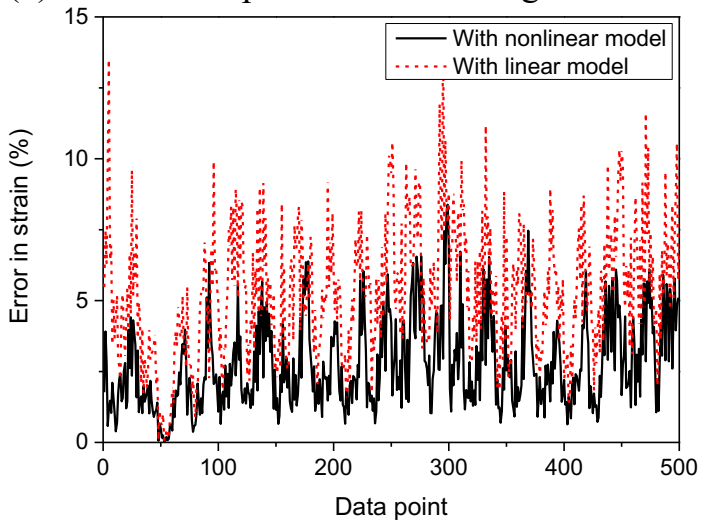

(d) Site at the middle span beam on the 2nd floor Figure 22 Errors in calculated results of strain history curves 